\title{
O PROGRAMA DE PROTEÇÃO AO EMPREGO INSTITUÍDO PELA LEI 13.189 /2015 EM CONTRAPONTO AO PRINCÍPIO CONSTITUCIONAL DO PLENO EMPREGO
}

\section{THE PROGRAM PROTECTION WORK ESTABLISHED BY LAW 13,189 / 2015 COUNTERPOINT IN THE CONSTITUTIONAL PRINCIPLE OF FULL EMPLOYMENT}

\author{
${ }^{1}$ Paulo Henrique Molina Alves \\ ${ }^{2}$ Luiz Eduardo Gunther
}

\section{RESUMO}

O presente estudo analisa o Programa de Proteção ao Emprego instituído pela lei 13.189 de 19.11.2015, trazendo toda a regulamentação existente a respeito da matéria, inclusive os atos do Poder Executivo Federal. Analisa os princípios constitucionais da ordem econômica, em especial quanto à valorização do trabalho humano e a busca do pleno emprego. Após, considera a atuação estatal na interferência das relações de trabalho em vista da redução coercitiva dos vencimentos dos empregados e trazendo reflexões a respeito da indagação inicial de ser ou não o Programa de Proteção ao Emprego uma medida balizada pelos ditames constitucionais de pleno emprego.

Palavras-chave: Programa de proteção ao emprego, Medida provisória 680 de 06.07.2015, Lei 13.189 de 19.11.2015, Pleno emprego

\begin{abstract}
This study analyzes and comments on the Employment Protection Program established bylaw 13.189 of 19.11.2015, bringing all the existing regulations on the matter, including the acts of the Federal Executive Government. It also analyzes the constitutional principles of economic order, especially regarding the development of human work and the pursuit of full employment. After considers the state action of interventionist at the labor relations in view of the coercive reduction salaries of employees and in the end brings some reflections on the initial question of whether or not the Employment Protection Programa measurebuoyedby the dictates constitutional full employment.
\end{abstract}

Keywords: Employment protection program, Provisional measure 680 of 07.06.2015, Law 13,189 of 11/19/2015, Full employment

1 Mestrando em Direito Empresarial e Cidadania do Centro Universitário Curitiba. Advogado e consultor atuante nas áreas de Direito do Trabalho e Direito Previdenciário. Centro Universitário Curitiba - UNICURITIBA, Paraná. Brasil - E-mail: paulohenriquemolina@yahoo.com.br

2 Doutor em Direito pela Universidade Federal do Paraná. Professor titular do Centro Universitário Curitiba. Centro Universitário Curitiba - UNICURITIBA, Paraná. Brasil - E-mail: 1uizgunther@trt9.jus.br 


\section{INTRODUÇÃOO}

O governo Dilma Roussef em resposta à grave crise econômica estabelecida em seu mandato anunciou a criação de um plano para evitar demissões em massa na indústria nacional, em clara tentativa de tentar conter outra crise instalada em sua administração: a de popularidade.

Neste contexto, foi instituído o Programa de Proteção ao Emprego - PPE, com objetivo de, segundo Medida Provisória que estabeleceu o $\operatorname{programa}^{1}$, possibilitar a preservação dos empregos em momentos de retração da atividade econômica, favorecer a recuperação econômico-financeira das empresas, sustentar a demanda agregada para facilitar a recuperação da economia, estimular a produtividade do trabalho por meio do aumento da duração do vínculo empregatício e fomentar a negociação coletiva a fim de aperfeiçoar as relações de emprego.

O PPE é um programa de redução temporária da jornada de trabalho onde o trabalhador tem seu salário proporcionalmente reduzido pela empresa, mas compensado parcialmente pelos cofres públicos. Tal instrumento ganhou notoriedade a partir da crise financeira de 2009, tomando como inspiração o governo brasileiro um programa adotado pela Alemanha, berço da indústria automobilística, que visava evitar layoffs excessivos durante a crise.

Dentre os motivos expostos para a criação do programa, os ministros da presidência apontam o PPE como vantajoso para todas as partes envolvidas: "para as empresas, permite ajustar seu fluxo de produção à demanda e, ao preservar os empregos, possibilita a manutenção de quadros já qualificados e a redução de custos com demissão e admissão. Para os trabalhadores, preserva os empregos e a maior parte de seus rendimentos. Para o governo, permite a economia com os gastos do seguro-desemprego e com outras políticas de mercado de trabalho ao mesmo tempo em que preserva a maior parte da arrecadação sobre a folha"2.

\footnotetext{
1 Medida provisória n. 680, de 06.07.2015-DOU 07.07.2015, artigo $1^{\circ}$.

2 Exposição de motivos à apresentação da Medida Provisória 680, EMI nº 00095/2015 MP MTE.
} 
Afora a discussão que remete à constitucionalidade de tal medida, há de se levar em conta que a tentativa do governo em evitar a situação de desemprego involuntário ou a sua duração pode ferir os princípios constitucionais de justiça social e de pleno emprego, sob o ponto de vista da atuação empresarial frente ao trabalhador, que poderá ver seu salário reduzido à sua revelia.

Em apertada síntese, o presente artigo pretende analisar e comentar o Programa de Proteção ao Emprego instituído pela medida provisória 680, em contraponto aos princípios constitucionais da ordem econômica, em especial quanto à valorização do trabalho humano e a busca do pleno emprego. Analisar-se-á também a interferência estatal nas relações privadas de trabalho, em vista da redução coercitiva dos vencimentos dos empregados. Ao final, pretende-se trazer um aclaramento à questão de ser ou não o Programa de Proteção ao Emprego uma medida balizada pelos ditames constitucionais de proteção ao trabalhador e de busca do pleno emprego.

\section{DO PROGRAMA DE PROTEÇÃO AO EMPREGO - PPE}

O Programa de Proteção ao Emprego - PPE, instituído pela medida provisória n. 680 de 06 de julho de 2.015 posteriormente convertida na lei 13.189 de 19 de novembro de 2015, visa resguardar a manutenção dos empregos dos trabalhadores das empresas que encontram-se em dificuldades financeiras por meio de redução temporária da jornada de trabalho, onde o trabalhador tem seu salário proporcionalmente reduzido pela empresa e compensado parcialmente peloscofres públicos.

Assim, as empresas que aderirem ao programa poderão reduzir temporariamente a jornada de trabalho de seus empregados (de toda a empresa ou de setor especifico) em até $30 \%$ (trinta por cento), ao passo queos salários são reduzidos na mesma proporção. Vale ressaltar que o Estado, por meio do Fundo de Amparo ao Trabalhador - FAT ${ }^{3}$ complementará até $50 \%$ (cinquenta por cento) da perda salarial, observado o limite de $65 \%$ do valor máximo da parcela do seguro-desemprego.

\footnotetext{
3 O Fundo de Amparo ao Trabalhador - FAT é um fundo especial, de natureza contábil-financeira, vinculado ao Ministério do Trabalho e Emprego - MTE, destinado ao custeio do Programa do Seguro-Desemprego, do Abono Salarial e ao financiamento de Programas de Desenvolvimento Econômico, conforme disposição no sitio eletrônico do Ministério, disponível em http://portal.mte.gov.br/fat/historico.htm
} 
Podem aderir ao PPE as empresas que se se encontram em situação de comprovada dificuldade econômico-financeira, permanecendo pelo período de até 24 (vinte e quatro) meses, respeitada a data de extinção do programa, prevista para o dia 31.12.2017.

De acordo com a Resolução n. 2/2015 do Comitê do Programa de Proteção ao Emprego - CPPE, entende-se por situação de dificuldade financeira:

Art. $4^{\circ}$ Será considerada em situação de dificuldade econômico-financeira, para fins do disposto no inciso IV do caput do art. $3^{\circ}$, a empresa cujo Indicador Líquido de Empregos - ILE for igual ou inferior a 1\%, apurado com base nas informações da empresa disponíveis no Cadastro Geral de Empregados e Desempregados - CAGED. $\S 1^{\circ}$ O ILE consiste no percentual representado pela diferença entre admissões e desligamentos, acumulada nos doze meses anteriores ao da solicitação de adesão ao PPE, em relação ao estoque de empregados.

$\S 2^{\circ}$ Para fins de apuração do ILE, será considerado o estoque de empregados verificado no $13^{\circ}$ mês anterior ao da solicitação de adesão ao PPE.

A redução da jornada e dos vencimentos dos trabalhadores está condicionada à celebração de acordo coletivo de trabalho específico ${ }^{4}$ com o sindicato de trabalhadores representativo da categoria da atividade econômica preponderante, aprovado por assembleia dos trabalhadores abrangidos pelo programa. É permitida a celebração do chamado Acordo Coletivo Múltiplo de Trabalho Específico a grupo de microempresas e empresas de pequeno porte, desde que partícipes do mesmo setor econômico, ressaltando-se que cada microempresa ou empresa de pequeno porte deverá, individualmente, demonstrar o cumprimento dos requisitos legais para a adesão ao PPE.

\footnotetext{
${ }^{4}$ Art. $5^{\text {o }}$. da lei 13.189/2015: O acordo coletivo de trabalho específico para adesão ao PPE, celebrado entre a empresa e o sindicato de trabalhadores representativo da categoria da atividade econômica preponderante da empresa, pode reduzir em até $30 \%$ (trinta por cento) a jornada e o salário.

$\S 1^{\mathrm{O}}-\mathrm{O}$ acordo deve ser aprovado em assembleia dos trabalhadores abrangidos pelo programa e deve dispor sobre:

I - número total de empregados abrangidos pela redução e sua identificação; II -

estabelecimentos ou setores específicos da empresa abrangidos;

III - percentual de redução da jornada e redução proporcional ou menor do salário;

IV - período pretendido de adesão ao PPE e de redução temporária da jornada de trabalho, que deve ter duração de até seis meses, podendo ser prorrogado por períodos de seis meses, desde que o período total não ultrapasse vinte e quatro meses;

$\mathrm{V}$ - período de garantia no emprego, que deve ser equivalente, no mínimo, ao período de redução de jornada acrescido de um terço;

VI - constituição de comissão paritária, composta por representantes do empregador e dos empregados

abrangidos pelo PPE, para acompanhar e fiscalizar o cumprimento do acordo e do programa, exceto nas microempresas e empresas de pequeno porte.

Art. $8^{\circ}$. do Decreto 8.479, de 06/07/2015 e Art. $5^{\circ}$ da Resolução n. 2, de 21/07/2015, do Comitê do Programa de Proteção ao Emprego - CPPE: (...)

$\S 1^{\circ} \mathrm{O}$ ACTE deverá ser aprovado em assembleia dos empregados a serem abrangidos pelo Programa.

$\S 2^{\circ}$ Para a pactuação do ACTE, a empresa demonstrará ao sindicato que foram esgotados os períodos de férias, inclusive coletivas, e os bancos de horas.

$\S 3^{\circ}$ Previamente à celebração do ACTE, a empresa fornecerá ao sindicato as informações econômico-financeiras a serem apresentadas para adesão ao PPE.

$\S 4^{\circ}$ As alterações no ACTE referentes a prazo, setores abrangidos e percentual de redução de jornada e salário, bem como as prorrogações da adesão, deverão ser registradas no sistema Mediador do Ministério do Trabalho e Emprego e submetidas à análise da SE-CPPE.
} 
Importante destacar que a compensação pecuniária de que trata a lei 13.189/2015 será paga sob a forma de benefício concedido a empregado da empresa participante do Programa $^{5}$, denominado Benefício PPE, com pagamento realizado pelo Ministério do Trabalho e Emprego - MTE, por intermédio da Caixa Econômica Federal, mediante depósito em conta bancária da empresa participante do PPE, que deverá transferir o valor do benefício aos empregados beneficiários do Programa, via crédito em folha de pagamento mensal da empresa $^{6}$.

Vale confirmar que os valores da compensação pecuniária a serem pagos no âmbito do Programa de Proteção ao Emprego - PPE comporão as bases de cálculo do INSS e do FGTS ${ }^{7}$, a fim de se evitar maiores perdas ao trabalhador. Além do mais, importante salientar que durante o período de adesão ao PPE a empresa, em regra, não poderá contratar empregados para executaras mesmas atividades exercidas pelos trabalhadores abrangidos pelo Programa, exceto nos casos de reposição ou aproveitamento de concluinte de curso de aprendizagem, desde que o novo empregado também seja abrangido pela adesão. Tal medida visa evitar fraudes ao programa, pois coíbe a contratação de mão de obra barata pela empresa, ao mesmo tempo que estimula o programa de aprendizagem.

\footnotetext{
${ }^{5}$ Conforme disposição do Artigo $1^{\circ}$ da Portaria 1.013, de 21 de julho de 2015 do MTE.

${ }^{6}$ Artigo $2^{\circ}$ da Portaria 1.013, de 21 de Julho de 2015 do MTE.

7 Conforme disposição do Art. 9. da lei 13.189/2015: “A compensação pecuniária integra as parcelas remuneratórias para efeito do disposto no inciso I do art. 22 e no $\S 8^{\circ}$ do art. 28 da Lei ${ }^{\circ} 8.212$, de 24 de julho de 1991, e do disposto no art. 15 da Lei n ${ }^{\circ} 8.036$, de 11 de maio de 1990."

${ }^{8}$ Lei n. 13.189, de 19.11.2015 - DOU 20.11.2015, artigo $7^{\circ}$.
} 
Em contrapartida aos benefícios concedidos pelo Estado às empresas em situação de dificuldade financeira que aderirem ao Programa, estas ficam proibidas de dispensar arbitrariamente ou sem justa causa os empregados que tiverem sua jornada de trabalho e remuneração temporariamente reduzidos enquanto vigorar a adesão ao Programa e, após o seu término, durante o prazo equivalente a um terço do período de adesão. Durante o período de adesão ao programa, também fica proibida a realização de horas extraordinárias pelos empregados abrangidos.

Dentre as inovações trazidas quando da conversão da medida provisória em lei, pode-se destacar a prioridade de adesão ao PPE às empresas que demonstrem cumprir com a cota para a contratação de pessoas com deficiência, medida esta que tem por objetivo estimular a pratica desta modalidade de contratação.

A empresa que aderir ao programa poderá denunciar o mesmo desde que comunique o ato ao sindicato que celebrou o acordo coletivo de trabalho específico, aos seus trabalhadores e ao Poder Executivo, com antecedência mínima de trinta dias, demonstrando as razões e a superação da situação de dificuldade econômico-financeira ${ }^{8}$, ocasião em que permanecerá a garantia de emprego, no entanto. Efetivada a denúncia, e após o decurso de novo prazo de 30 dias, a empresa poderá exigir de seus empregados o integral cumprimento da jornada de trabalho.

Ainda, de acordo com a lei $13.189 / 2015^{9}$, serão excluídas do PPE e ficarão impedidas de aderir novamente ao programa as empresas que:

\footnotetext{
I - descumprir os termos do acordo coletivo de trabalho específico relativo à redução temporária da jornada de trabalho ou qualquer outro dispositivo desta Lei ou de sua regulamentação; ou

II - cometer fraude no âmbito do PPE.

II - for condenada por decisão judicial transitada em julgado ou autuada administrativamente após decisão final no processo administrativo por prática de trabalho análogo ao de escravo, trabalho infantil ou degradante.

$\S 1$ A A empresa que descumprir o acordo coletivo ou as normas relativas ao PPE fica obrigada a restituir ao FAT os recursos recebidos, devidamente corrigidos, e a pagar multa administrativa correspondente a $100 \%$ (cem por cento) desse valor, calculada em dobro no caso de fraude, a ser aplicada conforme o Título VII da Consolidação das Leis do Trabalho - CLT, aprovada pelo Decreto-Lei $n^{\circ} 5.452$, de $1^{\circ}$ de maio de 1943 , e revertida ao FAT.
}

\footnotetext{
${ }^{9}$ Lei n. 13.189, de 19.11.2015 - DOU 20.11.2015, artigo $6^{\circ}$.
}

Segundo entendimento do Ministério do Planejamento, esse programa acarreta vantagens para todas as partes envolvidas (governo, trabalhadores e empresas). É o que se 
denota da apresentação do $\mathrm{PPE}^{10}$, onde o Ministro esclareceu ser o programa mais barato para o governo em vista de reduzir as despesas com o seguro-desemprego, layoff e intermediação de mão de obra, além de manter parte significativa da arrecadação com as contribuições sociais incidentes sobre os salários, além de que os recursos economizados poderiam ser revertidos em políticas para os trabalhadores mais vulneráveis. Sob a do trabalhador, as vantagens estão na manutenção do emprego no atual momento de crise, o que reserva o saldo no FGTS e o acesso ao seguro-desemprego para situações futuras, ao passo que as empresas beneficiadas podem evitar a perda de capital humano, aliviando assim o fluxo de caixa e reduzindo custos com demissão, contratação e treinamento.

\section{DA RELAÇÃO DE EMPREGO, DO PRINCIPIO CONSTITUCIONAL DO PLENO EMPREGO E DE SUA EFETIVIDADE NO ATUAL CENÁRIO ECONÔMICO}

Dente todas as modalidades de prestação de trabalho, a relação de emprego constituise na forma mais importante do sistema econômico contemporâneo, que tem na figura do empregado o núcleo do sistema normativo trabalhista. De acordo com os ensinamentos de José Augusto Rodrigues Pinto, o empregado é “o centro do sistema tutelar do direito do trabalho, encaixa-se no gênero trabalhador, cujo conceito pode assim ser formulado: aquele que utiliza a energia pessoal em proveito próprio ou alheio, visando a um resultado determinado, econômico ou não”. (PINTO, 2003, p. 107).

\footnotetext{
${ }^{10}$ Apresentação do programa pelo Ministério do Planejamento, disponível em: http://www.planejamento.gov.br/secretarias/upload/arquivo/assec/150713_-ppe.pdf, acessado em 03/08/2015.
} 
Por sua vez, caracteriza-se a relação de emprego pela presença dos elementos fáticos jurídicos de prestação de trabalho por pessoa física, não eventual, com pessoalidade, efetuada sob subordinação do tomador dos serviços e com onerosidade, conforme disposição dos $\operatorname{artigos} 2^{\circ}$. e $3^{\circ}$. da Consolidação das Leis do Trabalho, que definem empregador e empregado ${ }^{11}$.

A figura do trabalhador empregado teve especial proteção no texto Constitucional de 1988, que nos arts. $6^{\circ}$ ao 11 traz os principais preceitos relativos à matéria justrabalhista. Todavia, para o presente estudo, importa mencionar que a Constituição da República, ao tratar da ordem econômica, estabeleceu em seu bojo regras e limites para resguardar os direitos trabalhador, oferecendo-lhe oportunidade de vida digna por meio da inclusão pelo trabalho, conforme se infere da leitura do dispositivo:

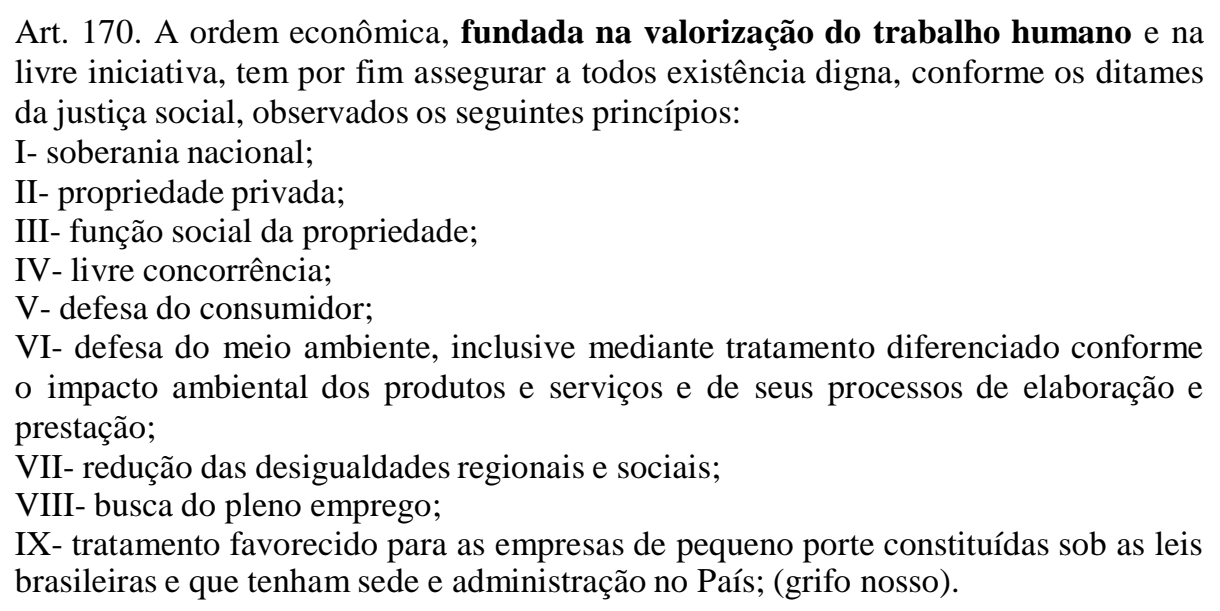

Na esteira do contido no artigo acima colacionado, André Ramos Tavares, comenta sobre a busca do pleno emprego, da seguinte maneira:

\begin{abstract}
A busca do pleno emprego figura como um princípio regulador da atividade econômica, implementado em algumas legislações infraconstitucionais, a partir de incentivos à iniciativa privada no sentido de criar e de manter os níveis de emprego (...) É princípio que se harmoniza e caminha no sentido de concretizar um dos fundamentos da ordem econômica, anteriormente mencionado, dirigido à valorização do trabalho humano, também com a justiça social e com a implementação de uma sociedade livre e igual. (TAVARES. 2011. p. 186).
\end{abstract}

\footnotetext{
${ }^{11}$ Consolidação das Leis do Trabalho - CLT, art. $2^{\circ}$., caput - "Considera-se empregador a empresa, individual ou coletiva, que, assumindo os riscos da atividade econômica, admite, assalaria e dirige a prestação pessoal de serviço".

Consolidação das Leis do Trabalho - CLT, art. $3^{\circ}$., caput - "Considera-se empregado toda pessoa física que prestar serviços de natureza não eventual a empregador, sob a dependência deste e mediante salário".
} 
Nessa toada, pode-se dizer que o pleno emprego decorre da democratização das relações de trabalho, definido como uma condição do mercado onde todos os que são aptos a trabalhar, e estão dispostos a fazê-lo, encontram trabalho remunerado, (ASSIS, 2002, p. 17) sendo um princípio da ordem econômica que visa criar oportunidades de trabalho para que todos possam viver dignamente, eliminando ou atenuando o déficit empregatício. (NAZAR, 2010. p. 66)

A compreensão dos motivos que conduziram o legislador constituinte a estabelecer a busca do pleno emprego como um dos elementos basilares da sistemática jurídica brasileira é tarefa bastante simples, pois é a atividade laboral que confere ao trabalhador a remuneração que por ele será utilizada para a digna subsistência sua e de sua família. É do montante pecuniário recebido pelo trabalhador que depende o sustento familiar, a educação dos filhos, os investimentos em moradia, saúde, lazer e, inclusive, o pagamento de tributos que serão utilizados pelo Estado para a manutenção da máquina pública, bem como para a realização de novos investimentos. (NITSCHKE JÚNIOR, 2008, p. 24).

Extrai-se do princípio em comento que o Estado deve prover e, se necessário, intervir na atividade econômica ou criar medidas de controle a fim de garantir a efetividade do inciso VIII do Art. 170 da Constituição, que no atual cenário de crise e crescimento do desemprego torna-se imperiosa sua manutenção. Todavia, alerta-se para a dificuldade de tornar efetiva a disposição constitucional, conforme palavras de Erivaldo Moreira Barbosa, que outrora já alertava para a problemática, que parece novamente se encaixar na atual conjuntura da economia brasileira. Confira-se:

\footnotetext{
“O inciso VIII refere-se ao 'pleno emprego', que fora insculpido no art. 170, mas, na concretude dos acontecimentos, vem sendo considerado quase como uma utopia. Afirmamos isto por causa da crescente onda de desemprego que vem assolando nosso País, em parte por questões relacionadas à automação capitalista via robótica e informatização; em parte, por fatores impostos pela nova ordem mundial e, em grande parte, por medidas internas de uma política econômica inconsistente, que, ao invés de priorizar as reais necessidades da sociedade, beneficia exclusivamente o grande capital privatista”. (BARBOSA, 2003, p. 206).
}

Em contraponto ao princípio constitucional em tela, Celso Ribeiro Bastos, (2004, p. 162), assevera que a redação texto constitucional é utópica e, praticamente inatingível, uma vez que a efetivação do pleno emprego é uma política de médio a longo prazo. Some-se a isso o fato de que o Brasil é um país de dimensões continentais, com inúmeras desigualdades regionais e com muitas políticas sociais de manutenção da subsistência, que acabam por interferir de maneira direta na efetivação do comando constitucional. 
Percebe-se que a Constituição brasileira criou direitos sociais sem prévia existência de recursos necessários à distribuição de riqueza pretendida, dependendo do fortalecimento do capitalismo e da economia de mercado como forma de obter os recursos e financiar os direitos sociais elencados no texto Constitucional. (AHRENS, 2013, p.22).

Além do mais, momentos de crise financeira e de instabilidade econômica como o que estamos passando acabam por fazer aumentar o número dos desempregados no país. É o que indica o Instituto Brasileiro de Geografia e Estatística, em pesquisa recente que aponta que a taxa de desemprego subiu até junho de 2015, chegando ao patamar histórico de 8,6\%, sendo a maior taxa da série histórica, que começou em 2012. Além disso, o contingente de desocupados em novembro de 2015 foi estimado em 1,8 milhão de pessoas no agregado das seis regiões investigadas, não variando na análise mensal (outubro de 2015). Em relação a novembro do ano anterior ocorreu acréscimo de 53,8\% de trabalhadores (mais 642 mil pessoas) em busca de trabalho formal ${ }^{12}$.

Além do memento de crise econômica que atravessa o país, há de se salientar também que existem outros fatores externos à relação de emprego que acabam por dificultar a efetividade do princípio em tela, como a alta carga tributária e o sistema jurídico de proteção aos empregados, que acabam por encarecer a relação de emprego. Naturalmente, os elevados custos - oriundos daexcessiva proteção legal e da elevada carga de impostos - tendem a dificultar, quando não inviabilizar, a contrataçãoformal dos trabalhadores, lançando boa parte da mão de obra para a informalidade e causando mais desemprego.

Sobre as situações adversas que impactam diretamente a concretização do pleno emprego no país, Magalhães afirma que:

\footnotetext{
${ }^{12}$ Indicadores IBGE, Pesquisa Mensal de Emprego, Novembro/2015.
} 


\begin{abstract}
Existe uma área na atividade empresarial chamada 'cinzenta', que se caracteriza por uma retração ou ociosidade dos empresários motivada por fatores econômicos gerais determinando a diminuição do seu poder aquisitivo de serviços, agravando suas repercussões sobre a mão de obra desocupada, conquanto qualificada para prestálos.

A solução desse círculo vicioso não pode ser outra senão fixar-se o governo no ponto a partir do qual o círculo se desenhou, qual seja o da falta de oportunidades produtivas ou sem atrativos, gerando a falta de pleno emprego. (MAGALHÃES, 1997, p. 248).
\end{abstract}

A existência de boa oferta de empregos (condição necessária aodesenvolvimento social), depende de estímulos para que os potenciaisempreendedores efetivamente se dediquem à exploração econômica deseus projetos. E isto somente ocorrerá se os riscos assumidos pelosempreendedores forem razoáveis. Riscos elevados (com envolvimento de seu patrimônio pessoal em caso de quebra) desestimulam o empreendedor, que deixa de aplicar seu capital em atividades produtivas que geram emprego no país. (TOKARS, 2007. p. 131).

Por esta razão é que principalmente em momentos de crise o Estado deve gerar políticas contingenciais para que seus efeitos não atinjam - demasiadamente - a população ativa do país, sem interferir, no entanto, a economia de mercado. Neste contexto de livre mercado compreende-se que a crise mundial de 2008 configurou um momento de ruptura e renovação típico do progresso não linear que altera ciclos de prosperidade e depressão característicos da história mundial (AHRENS, 2013, p.36), o que não é diferente no Brasil, que atualmente passa por situação deveras semelhante.

Parece claro que, frente à crise instaurada, o Estado deve prover medidas para garantir minimamente a manutenção dos empregos e, via de consequência, a dignidade de milhares de trabalhadores que dependem dos proventos do emprego para a manutenção própria e de seus familiares. Todavia, percebe-se que as primeiras medidas tomadas pelo atual governo para minimizar os impactos da crise foram de austeridade em que, em última análise, o trabalhador (principalmente os alocados na denominada classe média) foram os primeiros prejudicados, ante a alta generalizada de preços e impostos.

Importante destacar que não se pode perder de vista, evidentemente, que também existeno texto constitucionala previsão de direito ao desenvolvimento social e soberania nacional. O que se pretende enfatizar é que a pessoa humana é o sujeito central desse direito, sendo que, por esse motivo, não se poderá tomá-la como simples fator de produção. Pelo contrário, haverá a necessidade de se propiciar que o ser humano possa aferir frutos que possibilitem sua existência digna, que é a finalidade da própria ordem econômica e financeira, sendo responsabilidade do Estado a efetiva concretização do desenvolvimento. (PETTER, 
2005, p. 256-257).

\section{A IMPORTÂNCIA DA MANUTENÇÃO DAS RELAÇÕES DE EMPREGO EM MOMENTOS DE CRISE}

A maioria dos brasileiros, de acordo com uma visão predominantemente ocidental, costuma achar que "todo trabalho é digno". Mesmo que este signifique limpar o chão que alguém sujou, ainda assim é uma atividade vista como mais correta e bonita do que qualquer forma de roubo ou desonestidade. (MACIEL; GRILLO, 2009, p. 241).

Vivemos em uma sociedade do mérito, que de certa maneira pune severamente todas as pessoas que não se enquadram em determinado perfil social, reservando para estas os piores lugares na hierarquia moderna do status e da dignidade. O que está em jogo, na verdade, sem que paremos para pensar nisso, é uma luta constante, entre todas as pessoas, pelo reconhecimento de seu valor prático na sociedade do trabalho. É fundamental aqui a conexão entre respeito, condição e dignidade. Ela é a prova de que uma posição privilegiada na hierarquia moral do trabalho é um critério central para que as pessoas sejam respeitadas, o que significa serem consideradas naturalmente pelos outros como úteis e de valor. Esse respeito advindo do trabalho é indispensável para o bem-estar pessoal, além de assegurar na prática os direitos e o respeito formal da cidadania. (MACIEL; GRILLO, 2009, p. 257).

Para Hannah Arendt "o trabalho é a atividade correspondente ao artificialismo da existência humana, existência esta não necessariamente contida no eterno ciclo vital da espécie, e cuja mortalidade não é compensada por este último. O trabalho produz um mundo artificial de coisas nitidamente diferente de qualquer ambiente natural. Dentro de suas fronteiras habita cada vida individual". (ARENDT, 1987, p. 15).

Amartya Sem, ao tratar de mercados, liberdade e trabalho enfatiza a que "o mercado de trabalho pode ser libertador em muitos contextos diferentes, e a liberdade básica de transação pode ter uma importância crucial, independentemente do que o mecanismo de mercado vier ou não a realizar no que se refere a rendas, utilidades ou outros resultados". (SEN, 2000, p 141).

Para o jurista Miguel Reale, o trabalho é antes de tudo uma forma de criação de valores. Confira-se:

Ele já é, por si mesmo, um valor, como uma das formas fundamentais de objetivação do espírito enquanto transformador da realidade física e social, visto como o homem não trabalha porque quer, mas sim por uma exigência indeclinável de seu ser social, 
que é um "ser pessoal de relação", assim como não se pensa porque se quer, mas por ser o pensamento um elemento intrínseco ao homem, no seu processo existencial, que se traduz em sucessivas "formas de objetivação". Trabalho e valor, bem como, por via de consequiência, trabalho e cultura, afiguram-se termos regidos por essencial dialética de complementaridade. (REALE; BAGOLINI, 1997. p.11).

Em uma sociedade fundada em valores sociais constitucionalmente garantidos, o direito ao trabalho digno relaciona-se diretamente com o direito à inclusão e participação social, na medida em que aquele é a principal forma de inclusão e dignificação da pessoa humana, uma vez que da remuneração obtida por meio trabalho é que se consegue prover a aquisição dos bens indispensáveis à sobrevivência digna ${ }^{13}$.

Afora a questão da importância pessoal da empregabilidade, deve-se ressaltar, também, a importância social da geração e preservação de empregos, pois as pessoas que exercem atividade laborativa tendem a interferir positivamente na sociedade, auferindo renda, consumindo, promovendo a circulação de riquezas, gerando e recolhendo tributos, isto é, dando continuidade a um ciclo virtuoso de melhorias sociais. (NITSCHKE JÚNIOR, 2008, p. 24).

Além do mais, de maneira especial em períodos de crise econômica, a manutenção dos postos de trabalho é indispensável também para o Estado, que pode reduzir os gastos com o pagamento do seguro-desemprego e com outras políticas de mercado de trabalho, ao mesmo tempo em que preserva sensivelmente a arrecadação de impostos incidentes sobre a folha de salários.

\footnotetext{
${ }^{13}$ Nesse sentido ARENDT, Hannah, op. cit,., p. 223: "A suposição de que a identidade de uma pessoa transcende, em grandeza e importância, tudo o que ela possa fazer ou produzir é elemento indispensável da dignidade humana".
} 
Além do mais, o Estado deve proteger a população contra despedidas em massa a fim de se manter, também, o desenvolvimento e a manutenção sistema de seguridade social, como bem nos lembra Claudio Llanos Reyes (2015):

\begin{abstract}
La ocupación plena como requisito base para asegurar el desarrollo y continuidad del sistema de Seguridad Social implicaba que, frente a las dinámicas del capitalismo y sus crisis, la sociedad debía disponer de una suficiente demanda de trabajo, donde aquellos que perdieran sus empleos tardarían poco tiempo en reintegrarse a su labor anterior o en trabajar en una nueva relacionada con su capacidade (...) Una de las funciones que debe desempeñar el Estado en el futuro es la de asegurar la existencia de volumen adecuado de gastos y, por consiguiente, proteger a los ciudadanos contra la desocupación en masa"
\end{abstract}

Em assim sendo, fica claro que a manutenção dos postos de trabalho formais é fator indispensável para a manutenção da ordem social econômica de um Estado, quanto mais em tempos de crise, onde naturalmente os postos de trabalho tendem a diminuir e o desemprego aumentar. Isso implica em afirmar que não basta a Constituição Federal valorizar a busca pelo pleno emprego em seu texto, estabelecendo como regra matriz a ser seguida pela ordem econômica e social. Faz-se necessário, também, que a sistemática jurídica brasileira, como um todo, esteja direcionada para a materialização deste princípio, corrigindo-se os entraves que dificultam a busca do pleno emprego e procurando-se, com isso, promover o desenvolvimento econômico e reduzir as desigualdades sociais. (NITSCHKE JÚNIOR, 2008, p. 33).

Por esta razão, pretende-se no próximo ponto verificar algumas questões sobre a ação intervencionista do Estado que atingem as relações de emprego para criar condições de manutenção da empregabilidade e, em seguida, a adequação do termo pleno emprego à realidade social atual, com especial atenção ao novo Programa de Preservação do Emprego PPE.

\title{
5. DA AÇÃo INTERVENCIONISTA DO ESTADO NAS RELÇÕES DE EMPREGO PARA SUA MANUTENÇÃO
}

Neste trabalho não se pretende aprofundar no conceito de intervenção estatal, em questões históricas de formação do Estado Social caracterizado pela ordem constitucional de forte intervenção, nem do Estado Liberal, marcado pela eliminação de qualquer política intervencionista, tampouco tratar-se-á sobre o Estado de bem estar. Desse modo, importante estabelecer, desde já, que para o presente estudo, as medidas de intervenção estatal são as normas de conduta no sentido de gerir direta ou indiretamente o comportamento dos 
indivíduos ou empresas, prescrevendo como estes devem orientar suas relações cotidianas, inclusive as de trabalho. Tratam-se das práticas e políticas sociais denominadas por Emerson Gabardo (2010, p. 176-177), como sendo aquelas que se faz por meio da alocação obrigatória de um sistema de organização, serviços e ações nas áreas de saúde, trabalho, cultura e educação a fim de atingir principalmente a população mais vulnerável.

Nas palavras do autor:

\begin{abstract}
“cabe ao Estado de bem estar, como atividade que lhe é própria, responsabilizar-se pelo incremento civilizatório da sociedade, protegendo os indivíduos em face da possibilidade de retrocesso sociocultural, socioeconômico e socioambiental. (...) a face reguladora e interventora do Estado na economia é, portanto, imprescindível, ainda que deva ser muito bem delimitada na ordem constitucional". (2010, p. 176179).
\end{abstract}

No mesmo sentido, esclarece Bagnoli (2009, p. 273), que independentemente da condição de plenitude da sua soberania, cada Estado, por meio de sua soberania política e em defesa da soberania popular, deve atuar no controle do poder econômico, algo necessário para garantir o bom funcionamento de três setores que constituem o tripé de sustentação do Estado: trabalho, consumo e concorrência. Esses três setores acabam por pautar a condição socioeconômica da sociedade e, uma vez bem estruturados, traduzirão o bem-estar da coletividade.

Estabelecidas tais premissas, deve-se esclarecer que as intervenções do Estado, quando direcionadas às relações de emprego, visam - via de regra - proteger o trabalhador frente ao poderio do empregador, a fim de tutelar interesses maiores diretamente ligados ao bem comum que, no presente estudo, aponta-se à manutenção dos empregos formais e da busca do pleno emprego.

Como visto, numa acepção mais restrita, o pleno emprego seria definido como uma situação em que todos aqueles aptos a trabalhar estariam subordinados a uma relação de emprego. Hoje, com as mais diversas formas de exercício de atividade laboral e de vinculação com os agentes titulares dos meios de produção, a expressão plena emprego revela um sentido restritivo, sendo mais adequado diante dessa nova realidade socioeconômica, a substituição de seu termo por pleno trabalho ou plena atividade. (SANTOS, 2015). Em que pese o entendimento acima, para este estudo continuar-se-á a tratar do pleno emprego de maneira restrita, em vista de que aquele - o contrato de emprego - é o atingido pela Lei 13.189/2015.

Assim, a política de pleno emprego tem como resultado a progressiva eliminação das desigualdades sócio-econômicas, da pobreza e o aumento dos salários reais. Indiretamente, o pleno emprego contribui para a melhoria das condições de trabalho e do trabalhador e para a 
recuperação da economia e das finanças públicas. O Pleno Emprego é condição indispensável para construir uma sociedade efetivamente democrática, garantir o desenvolvimento nacional, erradicar a pobreza e a marginalização, e possibilitar aos que não dispõe de renda da propriedade a realização individual segundo suas potencialidades. Nesse sentido, é a contrapartida social do direito individual de propriedade, e a proteção constitucional daqueles que nascem sem direito a herança, mas com direitos de cidadania. (ASSIS, 2002, p. 122-123).

A Constituição Federal 1988 também garante a livre iniciativa pautada na valorização do trabalho humano, vinculado diretamente ao princípio da dignidade humana, de modo que a finalidade da atividade empresarial não pode estar direcionada somente ao lucro, mas também à existência digna, tudo nos termos do artigo 170. Apesar desta premissa Constitucional não ter aplicabilidade imediata, sua eficácia torna-se presente nas leis de proteção ao trabalhador, razão pela qual hoje se reconhece a importância da Intervenção do Estado na Economia a qual assegura a fonte de renda e a distribuição dela à população.

Nesse sentido, a Santa Sé, inclusive, em sua Encíclica Centesimus Annun, do Papa João Paulo II, reconhece que o

Estado deve concorrer tanto directa como indirectamente. Indirectamente e segundo o princípio de subsidiariedade, criando as condições favoráveis ao livre exercício da actividade económica, que leve a uma oferta abundante de postos de trabalho e de fontes de riqueza. Directamente e segundo o princípio de solidariedade, pondo, em defesa do mais débil, algumas limitações à autonomia das partes, que decidem as condições de trabalho, e assegurando em todo o caso um mínimo de condições de vida ao desempregado. (JOÃO PAULO II, 2016).

Há muito se fala na intervenção positiva do Estado nas relações de emprego com o intuito de fomentar investimentos de políticas públicas na educação e na qualificação profissional, a fim de se suprir o déficit do mercado de trabalhadores habilitados e capacitados para o trabalho. Ressalta Cattani (1991, p. 162-166), que o Brasil apresenta ineficiência dos 
trabalhadores, inclusive do trabalho desqualificado uma vez que os trabalhadores brasileiros não foram treinados a desenvolver a criatividade e a responsabilidade, pelo fato de o país ter- se regido durante o Século XX pelos princípios do modelo taylorista-fordista, fulcrado nas especializações rígidas e fragmentadas e na desqualificação do trabalho.

Inclusive, este é o entendimento de Cristiane Ferreira, abaixo colacionado:

Constata-se mais uma vez a necessidade da participação do Estado, por meio da criação e estruturação de programas que ofereçam qualificação ao trabalhador de acordo com as necessidades do mercado, além do investimento em educação de base para que o cidadão desenvolva sua capacidade criativa desde cedo. Somente a partir do momento em que o Estado passar a investir nos recursos humanos, o Brasil poderá inserir-se com dignidade no mercado global, das tecnologias avançadas. Caso contrário, estará sempre à margem dos países desenvolvidos, submetendo-se às suas regras, e assistindo à perda dos empregos e da dignidade de seus cidadãos. (FERREIRA, 2015).

Atualmente é bastante comum se encontrar, também, o entendimento no sentido de ausência de intervenção e regulação Estatal nas relações de emprego, a fim de se proporcionar maior flexibilidade nas relações contratuais de trabalho, considerada "engessada" por parte da doutrina especializada. Nesse sentido:

\begin{abstract}
A evidência internacional mostra que há uma forte relação entre o grau de proteção legal e o seu efetivo cumprimento: em geral, quanto mais intensa a regulação do mercado de trabalho, maior o grau de informalidade, menor a participação na força de trabalho e maior o desemprego, especialmente entre os trabalhadores mais jovens. O impacto da regulação sobre o mercado depende, portanto, de quão ajustada ela é à realidade econômica. Quanto menos ajustada, mais ela tenderá a ser ignorada, com uma conseqüência importante: exigir que as partes negociem e adotem as suas próprias regras, ao mesmo tempo que buscam escapar da fiscalização do setor público. (PINHEIRO, 2006, p. 166).
\end{abstract}

Todavia, pouco se fala quando a intervenção do Estado vem, supostamente, limitar ou restringir um direito consagrado e amplamente protegido em nosso ordenamento jurídico, como o direito à percepção do salário, corolário lógico do princípio do pleno emprego.

Como visto, uma das maneiras de se atingir o desenvolvimento sócio econômico, finalidade decorrente da política constitucionalmente adotada pelo Estado, é por meio da dignificação do trabalhador pela remuneração que seja capaz de lhe proporcionar a inclusão honesta de vida em sociedade e assegurar as condições necessárias para a consecução dos objetivos da ordem econômica por meio do pleno emprego. 
Neste diapasão, qualquer medida intervencionista deve ser analisada com cuidado, porquanto pode interferir diretamente na (qualidade de) vida do trabalhador. Por esta razão, os fins almejados pelo Estado quando da interferência na esfera dos contratos de trabalho devem justificar amplamente a media tomada, sob pena de se macular a segurança jurídica dos contratos de trabalho e do ordenamento jurídico como um todo.

Para a proposta do presente estudo, mais do que ser considerado um aspecto absolutamente negativo da crise econômica, a redução das horas de trabalho causada pelas políticas de repartição do trabalho pode ser vista como um desenvolvimento positivo. Nesse sentido, afirma Jon Messenger, pesquisador da OIT, em entrevista que comenta sobre plano de repartição parcido com o implementado pela Lei 13.189/2015:

\footnotetext{
“A repartição do trabalho é uma redução das horas laborais para evitar demissões. A empresa obtém uma redução temporária do gasto salarial e os empregados não perdem seu posto de trabalho. É uma medida que ajuda a estabilizar a economia"14
}

Embora a repartição do trabalho se traduza em uma redução proporcional dos salários, estes são substituídos em parte pelo seguro desemprego financiados pelo governo, quando ocorrem as demissões. Nesse sentido, afirmou o ministro da Secretaria Geral da Presidência "ser mais inteligente e correto financiar a manutenção do emprego do que financiar o desemprego" $" 15$.

Jon Messenger, analisando a sistemática dos programas de proteção ao emprego, também pondera que se forem observados somente os efeitos econômicos, se poderia supor que os salários diminuem proporcionalmente. Mas na maioria dos casos é dado um apoio à renda, seguro-desemprego ou indenização por desemprego, que subvencionam uma parte do salário reduzido. Além disso, afirma que os programas de compartilhamento de trabalho foram implantados em mais de vinte países nas Américas e na Europa, sendo uma medida temporáriaque permite que as empresas "respirem" até que comece a recuperação ${ }^{16}$.

\footnotetext{
$14 \mathrm{http} / / /$ www.oit.org.br/content/crise-causou-grandes-mudancas-nas-praticas-do-mercado-de-trabalho, acessado em $05 / 12 / 2015$.

15 Disse o ministro da Secretaria-Geral da Presidência, Miguel Rossetto, em entrevista à Agência Brasil em 07/07/2015, disponível em http://agenciabrasil.ebc.com.br/economia/noticia/2015-07/vamos-financiar-oemprego-em-vez-do-desemprego-diz-rossetto, acessado em 05/12/2015.

${ }^{16} \mathrm{http} / / / \mathrm{www}$.oit.org.br/content/crise-causou-grandes-mudancas-nas-praticas-do-mercado-de-trabalho, acessado em 05/12/2015.
} 
Em assim sendo, sob a ótica da ação intervencionista, deixando de lado as questões de fundo que deram origem à crise nacional, a política adotada pelo Estado em autorizar a redução dos salários dos trabalhadores em troca da manutenção do emprego parece acertada para o presente momento, uma vez que o trabalhador tem em troca a garantia provisória de emprego, instrumento valoroso, principalmente em tempos de crise.

\section{DO PRINCIPIO CONSTITUCIONAL DO PLENO EMPREGO EM CONTRAPONTO AO PROGRAMA DE PROTEÇÃO AO EMPREGO}

O direito ao trabalho não se esgota na simples liberdade ou possibilidade de trabalhar. Mais do que isso, passa também pelo direito de todos ao trabalho digno, de contraprestação justa e na outorga aos poderes públicos para que determinem políticas concretas à efetivação do pleno emprego ${ }^{17}$.

O princípio da valorização do trabalho estabelece a primazia do trabalho humano sobre o capital e os demais valores da economia de mercado. Disso, resulta que a atividade estatal deve ser norteada ela proteção de citada prioridade, além da promoção, em um sentido amplo, dos valores sociais do trabalho. (SILVA, 2001, p. 766). Tal promoção consiste em fundamento não só da ordem econômica, mas também da própria República Federativa do Brasil, conforme o art. $1^{\circ}$, IV, da Constituição, sem embargos de que constitui a valorização do trabalho humano pressuposto necessário à promoção da dignidade humana e da inclusão social.

Portanto, sem a observância da valorização do trabalho humano não é possível, na ordem econômica, concretizar a justiça social. Assim, o emprego deve ser garantido em igualdade de oportunidades e em estrita observância às garantias constitucionalmente afiançadas aos trabalhadores empregados, que em última análise permitirá a participação destes da vida em sociedade.

\footnotetext{
17 ASSIS, José Carlos de. Trabalho como direito: fundamentos para uma política de pleno emprego no Brasil. Rio de Janeiro: Contraponto, 2002, p. 13-14: “A busca pelo pleno emprego passa a ser reconhecida no Direito positivo com o objetivo de reduzir gradual e progressivamente a desigualdade e social decorrente do alto desempregocontemporâneo, tido como um fenômeno estrutural associado ao rápido desenvolvimento tecnológico das últimas décadas"
} 
Inexiste outro caminho, a não ser por meio da valorização do trabalho humano e, consequentemente, da concretização do pleno emprego, para que o combate às exclusões sociais seja eficaz, permitindo a observância da dignidade da pessoa humana como mecanismo de desenvolvimento socioeconômico do país. Por esta razão, as políticas intervencionistas adotadas devem ter a finalidade de tutelar a manutenção do trabalho, garantindo aos trabalhadores dignidade e inclusão.

Todavia, o favorecimento que a Constituição autoriza não pode ir além do equilíbrio determinado pelo princípio da igualdade, o que significa dizer que deverá ser respeitada a justa medida, indo tão-somente ao ponto necessário para compensar as fraquezas e as

inferioridades (BASTOS, 2004, p. 166), que o trabalhador enfrenta, principalmente em tempos de crise.

Como visto, o Programa de Proteção ao Emprego - PPE visa resguardar a manutenção dos empregos dos trabalhadores das empresas que encontram-se em dificuldades financeiras por meio de redução temporária da jornada de trabalho, onde o trabalhador tem seu salário proporcionalmente reduzido pela empresa e compensado parcialmente peloscofres públicos.

Por esta razão, o vínculo de emprego entre a empresa que apresenta dificuldades financeiras contingenciais e seus empregados deve ser mantido, visto que os números demonstram o aumento crescente do desemprego no país. Não bastasse, em que pese a diminuição temporária dos vencimentos, com a adesão das empresas ao Programa de Proteção o trabalhador terá seu emprego garantido, o que não o impede de buscar novas oportunidades no mercado de trabalho.

Ademais, deve-se frisar que o PPE é uma alternativa ao layoff (suspensão temporária do contrato de trabalho para requalificação profissional), ocasião em que o trabalhador é subsidiado pele seguro desemprego, o que muitas vezes gera uma redução maior de renda, além do que o empregado em layoff não tem estabilidade provisória de emprego, o que pode gerar demissões sem direito à percepção do benefício novamente.

Outra particularidade do Programa é a sua transitoriedade, já que a adesão da empresa terá duração máxima de 24 meses, além de que os empregados participantes serão compensados em parte pelo governo, sem a utilização do seguro-desemprego, que poderá ainda ser utilizado no caso de demissão após o período de estabilidade. 
Conclui-se, de todo modo, que em atendimento à determinação constitucional expressa, o caminho a ser trilhado para alcançar os objetivos para a erradicação da pobreza e redução das desigualdades sociais não é outro senão o desenvolvimento e aprimoramento do capitalismo e da economia de mercado. (AHRENS, 2013, p.22). Todavia, para trilhar este caminho, o primeiro passo é, sem dúvidas, a manutenção dos empregos, ainda que com redução parcial doa proventos, o que permite a estabilidade de mercado frente à crise instaurada.

Assim, compreende-se que frente aos dispositivos constitucionais acima analisados em contraponto ao PPEinstituído pela Medida Provisória n. 680, posteriormente convertida na lei 13.189/2015, além deconstituir incentivo direto à manutenção da empresa, estimula a efetividade do princípio do pleno emprego a partir da preservação dos contratos de trabalho, sem os quais o cidadão não pode garantir condições dignas de sobrevivência. Ademais, o tratamento estatal peculiariza-se na medida em que o trabalho passa a receber proteção não meramente filantrópica, porém politicamente racional, visto que titulares de capital e de trabalho são movidos por interesses distintos, ainda que se o negue ou se pretenda enuncia-los como convergentes ${ }^{18}$

\footnotetext{
${ }^{18}$ GRAU, Eros Roberto. A ordem econômica na Constituição de 1988, $13^{\mathrm{a}}$ ed., revista e atualizada. São Paulo: Malheiros Editores, 2008, p. 199.
} 


\section{CONSIDERAÇÕES FINAIS}

Em uma sociedade fundada em valores sociais constitucionalmente garantidos, o direito ao trabalho digno relaciona-se diretamente com o direito à inclusão e participação social, na medida que aquele é a principal forma de inclusão e dignificação da pessoa humana, uma vez que da remuneração obtida por meio trabalho é que provem a aquisição dos bens indispensáveis à sobrevivência digna.

Em assim sendo, fica claro que a manutenção dos postos de trabalho formais é fator indispensável para a manutenção da ordem social econômica de um Estado, quanto mais em tempos de crise, onde naturalmente os postos de trabalho tendem a diminuir e o desemprego aumentar. Isso implica em afirmar que não basta a Constituição Federal valorizar abusca pelo pleno emprego em seu texto, estabelecendo como regra matriz a serseguida pela ordem econômica e social. Faz-se necessário, também, que asistemática jurídica brasileira, como um todo, esteja direcionada para amaterialização deste princípio.

Sob este prisma, foi instituído o Programa de Proteção ao Emprego - PPE, com objetivo de possibilitar a preservação dos empregos no atual momento retração da atividade econômica e ajudar a recuperação econômico-financeira das empresas. Referido programa tem por finalidade resguardar a manutenção dos empregos por meio de redução temporária da jornada de trabalho e de salários, onde o trabalhador tem seusvencimentos proporcionalmente reduzidos e compensados parcialmente pelo governo.

Afora a discussão que remete à constitucionalidade de tal medida, deixando de lado, também, as questões de fundo que levaram o governo a estabelecer o PPE, há de se levar em conta que a tentativa do Estado em evitar a situação de desemprego involuntário ou a sua duração, além deconstituir incentivo direto à manutenção da empresa, estimula a efetividade do princípio do pleno emprego a partir da preservação dos contratos de trabalho, sem os quais o cidadão não pode garantir condições dignas de sobrevivência.

Portanto, sem a observância da valorização do trabalho humano não é possível, na ordem econômica, concretizar a justiça social. Assim, o emprego deve ser garantido em igualdade de oportunidades e em estrita observância às garantias constitucionalmente afiançadas aos trabalhadores empregados, que em última análise permitirá a participação destes da vida em sociedade. 
Em que pese que a medida adotada também ajude as empresas atingidas pela crise, percebe-se que o objetivo finalista do PPE é de preservação dos empregos, em estrita atenção à primazia do trabalho humano sobre o capital. Disso, resulta que a atividade estatal no caso em apreço foinorteadapela proteção dos valores sociais do trabalho.

Assim, percebe-se que a situação paliativa, qual seja, a de manter no mercado de trabalho, e por que não dizer, na sociedade, acaba por contribuir com a eficácia da busca do pleno emprego, em vista da situação de crise econômica experimentada.

Mais do que ser considerado um aspecto absolutamente negativo da crise econômica, a redução das horas de trabalho causada pelas políticas de repartição do trabalho pode ser vista como um desenvolvimento positivo, ante a manutenção dos postos de trabalho. Destarte, a implementação do Programa de Preservação dos Empregos - PPE é media que se impõe, a qual cria meios subsidiários de manutenção dos empregos e de estabilidade aos mesmos.

\section{REFERÊNCIAS BIBLIOGRÁFICAS}

ARENDT, Hannah - A Condição Humana. São Paulo. Universitária. 1987.

AHRENS, Luis Roberto. SÉLLOS-KNOERR, Viviane Coêlho de. Segurança institucional e desenvolvimento. Curitiba: $1^{\mathrm{a}}$ Ed. Clássica Editora, 2013.

ASSIS, José Carlos de. Trabalho como direito: fundamentos para uma política de pleno emprego no Brasil. Rio de Janeiro: Contraponto, 2002.

BARBOSA, Erivaldo Moreira. Direito constitucional: uma abordagem histórico-crítica. São Paulo: Madras, 2003.

BAGNOLI. Vicente. Direito e poder econômico. Rio de Janeiro : Elsevier, 2009. BASTOS,

Celso Ribeiro. Curso de Direito econômico. São Paulo: Celso Bastos, 2004. CATTANI,

Antonio David. A Ação Coletiva dos Trabalhadores. Porto Alegre: SM CulturaPalmarica, 1991.

FERREIRA, Cristiane Carvalho Burci. O papel do estado nas novas relações de trabalho surgidas a partir da globalização e do avanço tecnológico. Disponível em http://www.unimar.br/pos/trabalhos/arquivos/43362227df9d7616eee7f777397afcdc.pdf.

FERREIRA, Daniel. A licitação pública no Brasil e sua nova finalidade legal: a promoção do desenvolvimento nacional sustentável. Belo Horizonte: Fórum, 2102. 
GABARDO, Emerson. Interesse público e subsidiariedade: o Estado e a sociedade civil para além do bem e do mal. Belo Horizonte: Fórum, 2009.

GOMES. Magno Rogério; PEDROSO. Fabiano Prado; SOUZA. Solange de Cassia Inforzato de, SESSO FILHO, Umberto Antonio. Redução da Jornada de Trabalho e Impacto na Distribuição dos Salários Paranaenses em 2012.Revista paranaense de desenvolvimento, Curitiba, v.36, n.128, p.1-17, jan./jun. 2015. Disponível em http://www.ipardes.pr.gov.br/ojs/index.php/revistaparanaense/article/view/704, acesso em 02/01/2016.

GRAU, Eros Roberto. A ordem econômica na Constituição de 1988, 13 ${ }^{\mathrm{a}}$ ed., revista e atualizada. São Paulo: Malheiros Editores, 2008, p. 199.

JOÃO PAUlO II, Papa. Carta Encíclica Centesimus Annun, do Sumo Pontífice João Paulo II. Disponível em: http://w2.vatican.va/content/john-paul-ii/pt/encyclicals/documents/hf_jpii_enc_01051991_centesimus-annus.html\#_ftn45.

MACIEL, Fabrício; GRILLO, André. O trabalho que (in)dignifica o homem. In: SOUZA, Jessé (org.) A ralé brasileira: quem é e como vive - Belo Horizonte : Editora UFMG, 2009.

MAGALHÃES, Roberto Barcellos de. Comentários à Constituição Federal de 1988, V. II. Lúmen Júris. Rio de Janeiro, 1997.

NAZAR, Nelson. Direito Econômico. São Paulo. Edipro. 2010.

NITSCHKE JÚNIOR. Ademar. A atividade empresarial no Brasil e a ordem econômica na Constituição Federal de 1988 - a necessária harmonia para a promoção do desenvolvimento econômico e redução das desigualdades sociais. 2008. 186 f. Dissertação (Mestrado em Direito) - Centro Universitário Curitiba - UniCuritiba, Curitiba. 2008.

PETTER, Lafayete Josué. Princípios constitucionais da ordem econômica: o significado e o alcance do art. 170 da Constituição Federal. São Paulo: Revista dos Tribunais, 2005.

PINHEIRO, Armando Castelar; GIAMBIAGI, Fábio. Rompendo o marasmo: a retomada do desenvolvimento no Brasil. Rio de Janeiro: Elsevier, 2006.

PINTO, José Augusto Rodrigues. Curso de Direito Individual do Trabalho: noções fundamentais de direito trabalhista, sujeitos e institutos do direito individual. -5 . ed. São Paulo : LTR, 2003.

REALE, Miguel. In Introdução BAGOLINI, Luigi. Filosofia do trabalho. 2.ed. São Paulo: LTr, 1997.

REYS. Claudio Llnos. Seguridad social, empleo y propiedad privada en William Beveridge. Revista Historia Critica. Facultad de Ciencias Sociales · Universidad de los Andes. Bogotá, n. 56, Abril-Junio de 2015.2 Disponivel em http://historiacritica.uniandes.edu.co/indexar.php?c=Revista+No+56.

SANTOS, Boaventura de Souza. Pela mão de Alice: o social e o político na pósmodernidade. 12 ed. São Paulo: Cortez, 2008. 